\title{
Capacidade de combinação de linhagens avançadas e cultivares comerciais de melancia
}

\author{
Flávio de F Souza ${ }^{1}$; Rita de Cássia S Dias ${ }^{1}$; Manoel Abilio de Queiróz ${ }^{2}$ \\ 'Embrapa Semiárido, C. Postal 23, 56302-970 Petrolina-PE; flavio.franca@embrapa.br; rita.dias@embrapa.br; 2UNEB-DTCS, C. Postal \\ 171, 48905-680 Juazeiro-BA; manoelabiliomaq@gmail.com
}

\begin{abstract}
RESUMO
A análise da capacidade de combinação é uma ferramenta importante na estimação de parâmetros úteis ao melhoramento genético da melancieira; pois, auxilia na escolha de genitores, cruzamentos promissores e possibilita a caracterização da natureza e da magnitude da interação gênica envolvida na expressão dos caracteres de importância agronômica. Desse modo, o presente trabalho objetivou estimar os efeitos das capacidades de combinação geral (CGC) e específica (CEC), em seis genitores de melancia e seus nove híbridos, provenientes de um esquema de cruzamentos dialélicos parciais. $\mathrm{O}$ experimento foi realizado na Estação Experimental da Embrapa Rondônia, em Machadinho do Oeste-RO, no período de março a junho de 2005. Os genitores foram divididos em dois grupos, sendo o primeiro formado pelas linhagens Cpafro 34.305, Cpafro 74.105 e Cpafro 45.202, e o segundo, pelas cultivares comerciais 'Charleston Gray', 'Sugar Baby' e 'Omaru Yamato'. O desempenho dos tratamentos (genitores + híbridos) foi avaliado quanto a 11 caracteres agronômicos, utilizando-se delineamento em blocos ao acaso, com três repetições e parcelas de sete plantas. Os efeitos da CGC foram superiores aos da CEC para a maioria das características estudadas, evidenciando a predominância do efeito aditivo no controle gênico das mesmas. Na maioria dos genitores, foram verificados efeitos de CGC favoráveis ao melhoramento da cultura, sendo 'Sugar Baby' e 'Charleston Gray' os genótipos mais promissores para uso em estratégias de melhoramento intrapopulacional visando a obtenção de cultivares de frutos pequenos e grandes, respectivamente. Com base na CEC, as combinações híbridas superiores e portanto, com maior potencial de aproveitamento comercial foram Cpafro $74.105 \mathrm{x}$ Sugar Baby, de frutos pequenos e Cpafro 74.105 x Charleston Gray, de frutos grandes.
\end{abstract}

Palavras-chave: Citrullus lanatus, melhoramento genético, análise dialélica, efeitos aditivos.

\author{
ABSTRACT \\ Combining ability of advanced lines and marketable cultivars \\ of watermelon
}

The combining ability analysis is an important tool to estimate parameters used for superior genotype selection in breeding programs. Besides aiding in the choice of the best parents and promising hybrids, this technique enables the characterization of the nature and magnitude of gene expression related to agronomic traits of interest. This study aimed to estimate the effects of general combining ability (GCA) and specific combining ability (SCA) in a partial diallel cross of watermelon genotypes. The assay was carried out at the Experimental Station of Embrapa Rondônia, in Machadinho do Oeste, Rondônia state, Brazil. The parents were organized in two groups, the first being composed by three advanced lines: Cpafro 34.305, Cpafro 74.105 and Cpafro 45.202; and the second, by three cultivars: 'Charleston Gray', 'Sugar Baby' and 'Omaru Yamato'. Parents and hybrids were evaluated with regard to 11 agronomic traits. The study followed a randomized blocks design, with three replications, and seven plants per plot, spaced by $3.0 \mathrm{~m}$ between rows and $1.0 \mathrm{~m}$ between plants. The effects of GCA were superior than those of SCA to most traits, evidencing the predominance of the additive interaction on the control of those characters. Favorable GCA effects were verified on many parents, 'Sugar Baby' and 'Charleston Gray' being the most promising to intra-population breeding strategies aiming to develop smaller and larger fruit varieties, respectively. On the basis of the SCA effects, Cpafro $74.105 \times$ Charleston Gray (large fruits) and Cpafro 74.105 x Sugar Baby (small fruits) were the best combinations, presenting more potential to commercial cultivation.

Keywords: Citrullus lanatus, genetic breeding, diallel analysis, additive effects.

(Recebido para publicação em 2 de agosto de 2013; aceito em 1 de novembro de 2013) (Received on August 2, 2013; accepted on November 1, 2013)

\begin{abstract}
A melancia (Citrullus lanatus) pertence à família Cucurbitaceae, da qual também fazem parte outras espécies hortícolas de importância comercial, como melão, abóbora, jerimum, pepino, chuchu e maxixe. É um alimento saudável, refrescante diurético, de baixo teor calórico, rico em água e que funciona como uma excelente fonte de sais minerais e vitaminas (sobretudo A, B1 e B2), que ajudam a manter a integridade
\end{abstract}

da pele e do sistema nervoso e auxiliam no metabolismo dos carboidratos. Além disso, a polpa vermelha é rica em licopeno, um pigmento antioxidante, que exerce importante papel na prevenção contra o câncer e contra doenças do coração (Gama \& Viza, 2008).

A China destaca-se como o principal produtor, tendo atingido em 2011, a marca de 69,57 milhões de toneladas de frutos. No mesmo ano, o Brasil, com uma produção de 2,20 milhões de toneladas, ocupou a $4^{\mathrm{a}}$ posição no ranking mundial (FAO, 2013). Os principais estados produtores foram RS (421.647 t), BA (292.432 t), GO (272.650 t) e SP (242.586 $\mathrm{t}$ ), que juntos responderam por cerca de $56 \%$ da produção brasileira (IBGE, 2013). Rondônia ocupa apenas a $19^{\text {a }}$ colocação no ranking nacional, com uma produção de 9.922 toneladas de melancias, em 2011. Naquele es- 
tado, a produção advém basicamente de dois sistemas de cultivo: em "áreas de várzea", no qual as lavouras são implantadas pelos ribeirinhos, entre os meses de maio e setembro, com baixíssimo emprego de tecnologia, sendo 'Charleston Gray' e 'Fair Fax' as principais cultivares utilizadas; e em "terra firme", que é realizado sob irrigação, por pequenos e médios produtores, com maior utilização de insumos, inclusive sementes certificadas da cultivar 'Crimson Sweet' e seus híbridos (Souza, 2008). Embora pequena, a produção estadual de melancia constitui importante fonte de renda e empregos.

No ano de 2002, iniciou-se na Embrapa Rondônia um programa de melhoramento genético visando ao desenvolvimento e avaliação de genótipos de melancia produtivos, precoces e com características diferenciadas em relação às cultivares predominantes no mercado nacional, sobretudo no que concerne à cor da polpa, padrão de casca, tamanho de fruto, tamanho e quantidade de sementes (Souza, 2008). Nesse caso, a realização de estudos genéticos é ferramenta imprescindível na escolha dos genitores, bem como na definição das técnicas de condução das populações segregantes. A análise da capacidade combinatória dos potenciais genitores permite identificar aqueles mais aptos para transmitir os caracteres desejáveis à descendência, bem como auxilia na escolha dos cruzamentos mais promissores para exploração comercial. A capacidade geral de combinação (CGC) é estimada com base no desempenho médio de um genitor quando cruzado com outros e está associada à presença de efeitos aditivos dos alelos e às associações epistáticas do tipo aditiva. Por outro lado, a capacidade específica de combinação (CEC) refere-se a uma combinação particular entre dois genitores cujo desempenho está acima ou abaixo do esperado com base no desempenho médio de ambos e está associada aos efeitos de dominância e epistasia envolvendo dominância (Griffing, 1956; Cruz \& Vencovsky, 1989). Uma maneira de se estimar as capacidades geral e específica de combinação de genitores é por meio da realização de cruzamentos dialélicos parciais, os quais se baseiam nas condições gênicas entre genitores pertencentes a diferentes grupos, sendo estes últimos divergentes em um ou mais caracteres (Cruz et al., 2004).

Em melancia, alguns estudos para avaliação da capacidade geral e específica de combinação têm sido realizados em diversos países, como Egito (Sachan \& Nath, 1976; Shaban \& Abdelssalam, 2009), Índia (Nandpuri et al., 1975; Brar \& Sidu, 1977; Sidhu \& Brar, 1977; Gill \& Kumar, 1988), Brasil (Ferreira et al., 2002; Souza et al., 2002; 2004), Sérvia (Gvozdanovic-Varga et al., 2011) e Malásia (Bahari et al., 2012). Esses estudos têm fornecido informações importantes na condução dos programas de melhoramento genético que utilizam o germoplasma avaliado.

Mediante o exposto, este trabalho teve como objetivo, estimar as capacidades geral e específica de combinação entre seis genitores e nove híbridos de melancia para obtenção de parâmetros genéticos úteis ao programa de melhoramento da espécie, conduzido na Embrapa.

\section{MATERIAL E MÉTODOS}

O experimento foi implementado nos meses de março a junho de 2005, na EE da Embrapa Rondônia, localizada no município de Machadinho do Oeste-RO (09 23'44'S; 6201'17'O; 219 m de altitude). O clima da microrregião é tropical úmido, do tipo Am (Köppen), apresentando precipitação anual de $2.200 \mathrm{~mm}$, temperatura média anual de $24,9^{\circ} \mathrm{C}$ e, em média, $80 \%$ de umidade relativa do ar. O solo é do tipo latossolo amarelo e relevo plano, com as características químicas: $\mathrm{pH}$ em água $=5,7$; fósforo $=6,0 \mathrm{mg} / \mathrm{dm}^{3}$; potássio $=3,05$ $\mathrm{mmolc} / \mathrm{dm}^{3}$; cálcio $=14,9 \mathrm{mmolc} / \mathrm{dm}^{3}$; magnésio $=5,1 \mathrm{mmolc} / \mathrm{dm}^{3} ; \mathrm{Al}+\mathrm{H}=72,6$ $\mathrm{mmolc} / \mathrm{dm}^{3}$, alumínio $=3,1 \mathrm{mmolc} / \mathrm{dm}^{3}$ e saturação de bases $=24 \%$.

Empregou-se o delineamento em blocos ao acaso, com três repetições e parcelas de sete plantas, em fileira única. $\mathrm{O}$ espaçamento utilizado foi de 3,0 m entre fileiras e 1,0 m entre plantas. Os tratamentos consistiram de seis genitores, divididos em dois grupos, e de nove combinações híbridas. O grupo I constituiu-se de três linhagens avançadas do programa de melhoramento genético da Embrapa Rondônia, denominadas: Cpafro 34.305, Cpafro 74.105 e Cpafro 45.202. O grupo II foi constituído pelas cultivares 'Charleston Gray', 'Sugar Baby' e 'Omaru Yamato'. Os híbridos foram obtidos na $\mathrm{EE}$ de Machadinho do Oeste, no período de setembro a dezembro de 2004 , por meio de polinizações artificiais, utilizando-se as linhagens como receptoras e as cultivares como doadoras de pólen.

A semeadura foi realizada diretamente no solo, as adubações foram feitas com base na análise do solo e todos os tratos culturais e fitossanitários foram realizados com base nas recomendações técnicas para a cultura no estado (Souza, 2008). A colheita foi realizada aos 70 dias após a semeadura.

Foram avaliadas as seguintes características: 1) massa média do fruto (MF), em $\mathrm{kg}$, utilizando balança eletrônica com capacidade para até $15 \mathrm{~kg}$; 2) teor de sólidos solúveis no centro da polpa (SS), em ${ }^{\circ}$ Brix, utilizando refratômetro manual; 3) diâmetro transversal (DT) e 4) diâmetro longitudinal do fruto (DL), em $\mathrm{cm}$, medindo-se com uma régua, respectivamente, a menor e a maior dimensão do fruto, cortado longitudinalmente; 5) espessura da casca na região da cicatriz floral (EF) e na 6) região do pedúnculo $(\mathrm{EP})$, em $\mathrm{cm}$, medindo-se com uma régua, nos dois extremos do fruto, cortado longitudinalmente; 7) número de sementes por fruto (NS); 8) massa de semente (MS), em $\mathrm{mg}$, pesando-se 100 sementes por fruto, em balança eletrônica de precisão; 9) largura de semente (LS) e 10) comprimento de semente (CS), em mm, medidas com paquímetro digital, em 10 sementes por fruto; e 11) número de frutos por planta (NF). Para obtenção das médias dos caracteres de fruto, foram amostrados dois frutos em cada parcela, tomados ao acaso durante a colheita. Por outro lado, a prolificidade média foi determinada tomando-se todas as plantas da parcela.

A análise de variância do dialelo foi realizada segundo o modelo de Griffing (1956), adaptado para dialelos parciais: $Y_{i j}=\mu+g_{i}+g_{j}^{\prime}+s_{j}+\bar{\varepsilon}_{j}$, sendo, $\mathrm{Y}_{\mathrm{ijk}}$ o valor médio da combinação hí- 
brida envolvendo o i-ésimo genitor do grupo I e o j-ésimo genitor do grupo II; $\mu$, a média geral do dialelo; $g_{i}$, o efeito da capacidade geral de combinação do i-ésimo genitor do grupo I; g', o efeito da capacidade geral de combinação do $\mathrm{j}$-ésimo genitor do grupo II; $\mathrm{s}_{\mathrm{ij}}$, o efeito da capacidade específica de combinação do i-ésimo genitor do grupo I e o j-ésimo genitor do grupo II e $\bar{\varepsilon}_{i j}$, o erro experimental. Os cálculos da análise de variância e estimativas da capacidade de combinação foram realizados por meio do aplicativo Genes (Cruz, 2013).

\section{RESULTADOS E DISCUSSÃO}

Por meio da análise de variância (Tabela 1), verificaram-se diferenças significativas entre os tratamentos para todas as variáveis, evidenciando a existência de considerável variabilidade fenotípica entre os mesmos. Os grupos de genitores, reunidos em linhagens avançadas (grupo I) e cultivares comerciais (grupo II), respectivamente, diferiram estatisticamente entre si para a maioria das variáveis, exceção feita apenas ao diâmetro transversal do fruto (DT). Esse resultado expressa o contraste entre os dois grupos e justifica a análise mais aprofundada dos seus intercruzamentos, pois a hibridação de genitores divergentes e de alta performance, geralmente, propicia maior heterose na progênie e aumenta as chances de recuperação de genótipos superiores nas gerações segregantes (Cruz et al., 2004). Também se verificou grande variabilidade intragrupo. No grupo I, cujas linhagens foram derivadas do cruzamento entre 'Sugar Baby’ e 'Kodama’ (Souza, 2008), foram observadas diferenças significativas para todas as variáveis, exceto para diâmetro longitudinal do fruto e aos caracteres relacionados com o tamanho das sementes (MS, LS e CS), demonstrando que, embora compartilhem do mesmo background genético, as linhagens apresentam características fenotípicas distintas. No grupo II, diferenças significativas não foram verificadas apenas para massa e diâmetro transversal do fruto, o que confirma a diversidade deste grupo, que é composto por cultivares divergentes. Os cruzamentos também diferiram para a maioria das variáveis, com exceção dos sólidos solúveis e do diâmetro transversal do fruto.

Com base na análise de variância da capacidade combinatória dos genitores (Tabela 1), verificaram-se efeitos significativos da CGC, no grupo I, apenas para o comprimento da semente, o que demonstra certa similaridade genotípica entre as linhagens deste grupo, a despeito da diversidade fenotípica observada na análise de variância baseada no desempenho per se das mesmas. No grupo II, efeitos significativos de CGC foram observados para diâmetro longitudinal do fruto, bem como para massa, comprimento e largura das sementes. Nesse caso, destaca-se que esses resultados devem-se, sobretudo à presença da cultivar 'Charleston Gray', no grupo II,

Tabela 1. Análise de variância, baseada em um esquema de cruzamentos dialélicos parciais envolvendo seis genótipos de melancia (analysis of variance, based on a partial diallel cross experiment with six parents of watermelon). Machadinho do Oeste, Embrapa Semiárido, 2005.

\begin{tabular}{|c|c|c|c|c|c|c|c|c|c|c|c|c|}
\hline \multirow{2}{*}{$\begin{array}{l}\text { Fonte de } \\
\text { Variação }\end{array}$} & \multirow[b]{2}{*}{ GL } & \multicolumn{11}{|c|}{ Quadrados médios } \\
\hline & & $\begin{array}{l}\mathbf{M F}^{1} \\
(\mathrm{~kg})\end{array}$ & $\begin{array}{c}\text { SS } \\
\left({ }^{\circ} \text { Brix }\right)\end{array}$ & $\begin{array}{c}\text { DL } \\
(\mathrm{cm})\end{array}$ & $\begin{array}{l}\text { DT } \\
(\mathrm{cm})\end{array}$ & $\begin{array}{c}\mathrm{EF} \\
(\mathrm{cm})\end{array}$ & $\begin{array}{c}\text { EP } \\
(\mathrm{cm})\end{array}$ & $\begin{array}{l}\text { NS } \\
\text { (u) }\end{array}$ & $\begin{array}{c}\text { MS } \\
(\mathrm{mg})\end{array}$ & $\begin{array}{c}\text { LS } \\
(\mathbf{m m})\end{array}$ & $\begin{array}{c}\mathrm{CS} \\
(\mathrm{mm})\end{array}$ & $\begin{array}{l}\text { NF } \\
\text { (u) }\end{array}$ \\
\hline Tratamentos & 14 & $1,86^{* *}$ & $2,73 * *$ & $25,28 * *$ & $5,17^{*}$ & $0,049 \mathrm{~ns}$ & $0,24 * *$ & $40416,13^{* *}$ & $2,34 * *$ & $11,62 * *$ & $26,97 * *$ & $12,57 * *$ \\
\hline Genitores $(\mathrm{G})$ & 5 & $1,04^{* *}$ & $6,49 * *$ & $32,22 * *$ & $3,98 \mathrm{~ns}$ & $0,057 \mathrm{~ns}$ & $0,43^{* *}$ & $26207,24^{* *}$ & $5,25 * *$ & $10,03 * *$ & $22,73 * *$ & $4,08^{* *}$ \\
\hline Grupo I & 2 & $2,33 * *$ & $2,58^{*}$ & $12,97 \mathrm{~ns}$ & $9,09 *$ & $0,093 \mathrm{~ns}$ & $0,14 *$ & $35239,33^{* *}$ & * $0,02 \mathrm{~ns}$ & $0,02 \mathrm{~ns}$ & $0,23 \mathrm{~ns}$ & $2,43 * *$ \\
\hline Grupo II & 2 & $0,26 \mathrm{~ns}$ & $5,89 * *$ & $53,56^{* *}$ & $0,54 \mathrm{~ns}$ & $0,043 \mathrm{~ns}$ & $0,38^{* *}$ & $25834,55^{*}$ & $12,62 * *$ & $8,07 * *$ & $18,03 * *$ & $1,10^{* *}$ \\
\hline G1 vs G2 & 1 & $0,01 \mathrm{~ns}$ & $15,51 * *$ & $28,05 \mathrm{~ns}$ & $0,65 \mathrm{~ns}$ & $0,013 \mathrm{~ns}$ & $1,14 * *$ & $8888,44 \mathrm{~ns}$ & $0,98^{*}$ & $1,94 * *$ & $4,47 * *$ & $0,54^{*}$ \\
\hline $\mathrm{G} \times \mathrm{C}$ & 1 & $7,19^{* *}$ & $0,04 \mathrm{~ns}$ & $31,07^{*}$ & $12,19^{*}$ & $0,108 \mathrm{~ns}$ & $0,20 *$ & $9744,86 \mathrm{~ns}$ & $0,58 \mathrm{~ns}$ & $0,41^{* *}$ & $0,13 \mathrm{~ns}$ & $1,85^{* *}$ \\
\hline Cruzamentos $(\mathrm{C})$ & 8 & $1,70 * *$ & $0,72 \mathrm{~ns}$ & $20,22^{*}$ & $5,04 \mathrm{~ns}$ & $0,036 \mathrm{~ns}$ & $0,12 * *$ & 53130 & * $0,74 * *$ & $1,19 * *$ & $4,11 * *$ & $6,65^{* *}$ \\
\hline CGC G1 & 2 & $1,84 \mathrm{~ns}$ & $0,07 \mathrm{~ns}$ & $3,75 \mathrm{~ns}$ & $3,63 \mathrm{~ns}$ & $0,021 \mathrm{~ns}$ & $0,01 \mathrm{~ns}$ & $9094,75 \mathrm{~ns}$ & $0,64 \mathrm{~ns}$ & $0,05 \mathrm{~ns}$ & $1,04^{*}$ & $0,23 \mathrm{~ns}$ \\
\hline CGC G2 & 2 & $3,56 \mathrm{~ns}$ & $1,22 \mathrm{~ns}$ & $70,68 * *$ & $12,71 \mathrm{~ns}$ & $0,042 \mathrm{~ns}$ & $0,34 \mathrm{~ns}$ & $136787,45 \mathrm{~ns}$ & $2,09 * *$ & $1,06^{* *}$ & $2,79 * *$ & $1,62 \mathrm{~ns}$ \\
\hline CEC & 4 & $0,71^{*}$ & $0,80 \mathrm{~ns}$ & $3,23 \mathrm{~ns}$ & $1,91 \mathrm{~ns}$ & $0,041 \mathrm{~ns}$ & $0,06 \mathrm{~ns}$ & $33320,09^{* *}$ & * $0,11 \mathrm{~ns}$ & $0,07 \mathrm{~ns}$ & $0,28 \mathrm{~ns}$ & $4,79^{* *}$ \\
\hline \multirow[t]{2}{*}{ Resíduo } & 28 & 0,19 & 0,53 & 6,96 & 2,32 & $0,020 \mathrm{~ns}$ & 0,03 & 5173,49 & 0,21 & 1,28 & 3,36 & 2,09 \\
\hline & \multicolumn{12}{|c|}{ Componentes quadráticos } \\
\hline CGC C & & 0,13 & $-0,08$ & 0,06 & 0,19 & 0,00 & $-0,01$ & $-2691,70$ & 0,06 & 0,00 & 0,05 & $-0,12$ \\
\hline CGC Grupo II & & 0,32 & 0,05 & 7,50 & 1,20 & 0,00 & 0,03 & 11496,37 & 0,22 & 0,06 & 0,15 & $-0,04$ \\
\hline Média (G1 e G2) & & 0,22 & $-0,02$ & 3,78 & 0,70 & 0,00 & 0,01 & 4402,33 & 0,14 & 0,03 & 0,10 & $-0,08$ \\
\hline CEC & & 0,17 & 0,09 & $-1,24$ & $-0,14$ & 0,01 & 0,01 & 9382,20 & $-0,03$ & $-0,01$ & $-0,02$ & 0,37 \\
\hline
\end{tabular}

ns, *, ** Não significativo e *significativo, ao nível de 5 e $1 \%$ de probabilidade, pelo teste F, respectivamente ('ns' means 'not significant' and $*$, ** significant by $\mathrm{F}$ test at $\mathrm{p}<0.05$ and $\mathrm{p}<0.01$, respectively). ${ }^{1} \mathrm{MF}=$ massa do fruto (fruit weight), $\mathrm{SS}=$ sólidos solúveis (soluble solid content), $\mathrm{DL}=$ diâmetro longitudinal do fruto (axial diameter of fruit), $\mathrm{DT}=$ diâmetro transversal do fruto (transversal diameter of fruit), $\mathrm{EP}=$ espessura da casca na região do pedúnculo (rind thickness under the stalk), $\mathrm{EP}=$ espessura da casca na região da cicatriz floral (rind thickness under petals scar), NS= número de sementes por fruto (number of seeds per fruit), MS= massa da semente (seed weight), LS= largura da semente (seed width); $\mathrm{CS}=$ comprimento da semente (seed length) e $\mathrm{NF}=$ número de frutos por planta (number of fruits per plant). 
que apresenta frutos elípticos e sementes grandes (Souza, 2008).

Efeitos significativos de CEC foram verificados apenas para massa de frutos, número de sementes e número de frutos por planta. Inclusive, os componentes quadráticos da CEC superam os da CGC apenas no caso destas variáveis (Tabela 1), o que indica haver, no controle das mesmas, predominância de ação gênica não-aditiva, enquanto que nos demais predomina a ação gênica aditiva. Esses resultados contrastam com os observados por Souza et al. (2002) e Ferreira et al. (2002) que verificaram predominância de ação aditiva para aqueles caracteres. Por outro lado, Shaban \& Abdelssalam (2009) e Bahari et al. (2012), estudando a capacidade combinatória de genitores de melancia de distintas origens e sob diferentes ambientes, observaram um predomínio dos efeitos de CGC para a maioria dos caracteres, com exceção do número de frutos por planta, para o qual os efeitos de CEC foram superiores. Souza et al. (2004), estudando algumas populações que originaram as linhagens do grupo I, constataram predominância de efeitos não-aditivos no controle do número de frutos por planta, também concordando com os resultados obtidos no presente estudo. Gusmini \& Wehner (2005) atribuem as discrepâncias dos resultados de diferentes estudos de análise combinatória em melancia ao número reduzido de genitores testados e à forma não aleatória de amostragem dos genitores. Segundo esses autores, os resultados obtidos nessas circunstâncias são válidos apenas para os cruzamentos avaliados e não podem ser extrapolados.

O predomínio da ação gênica aditiva para determinado caractere favorece o melhoramento genético por meio de seleção, pois um indivíduo ou grupo de indivíduos superiores quando selecionados produzirão uma descendência também superior enquanto que a interação de dominância dificulta a seleção de indivíduos superiores, uma vez que a descendência deste indivíduo terá comportamento inferior ao dele próprio. Por outro lado, efeitos não-aditivos podem ser explorados na obtenção de combinações híbridas promissoras, pois a interação de dominância favorece a obtenção de híbridos superiores, sobretudo aqueles oriundos de genitores com efeitos favoráveis de CGC.

A prolificidade é um importante componente da produtividade e é fundamental para as cultivares de frutos pequenos, nos quais, o fato de terem menor massa por unidade deve ser compensado por uma maior quantidade de unidades produzidas. Pela prevalência dos resultados que apontam para o controle não- -aditivo do número de frutos por planta, em diversos estudos, espera-se que esta característica possa ser incorporada a futuros híbridos comerciais de melancia pelo uso de genitores prolíficos nos cruzamentos.

A linhagem Cpafro 34.305 apresentou efeitos negativos de CGC para massa e diâmetro (DL e DT) de fruto; espessura de casca (EF e EP); massa, comprimento e largura de sementes. Por outro lado, efeitos positivos foram verificados sólidos solúveis, número de sementes e número de frutos por planta (Tabela 2). Com base nestes resultados, infere-se que, quando utilizado em estratégias intrapopulacionais de melhoramento, este genitor tende a contribuir para a obtenção de progênies mais prolíficas, com frutos de menor tamanho, mais doces, de casca mais fina e com sementes numerosas e menores. Considerando que no mercado atual a preferência é por frutos menores, mas com menor número de sementes, conclui-se que este genitor não seria adequado para a seleção de genótipos superiores.

A linhagem Cpafro 74.105 apresentou efeitos de CGC negativos para massa, comprimento e largura de fruto, número e largura de sementes e positivo para sólidos solúveis, espessura de casca, massa de sementes e número de frutos, indicando que nos cruzamentos

Tabela 2. Estimativa dos efeitos da capacidade geral de combinação de seis genitores de melancia, para 10 características agronômicas (estimates of the effects of general combining ability in six parents of watermelon, for 10 agronomic traits). Machadinho do Oeste, Embrapa Semiárido, 2005.

\begin{tabular}{|c|c|c|c|c|c|c|c|c|c|c|c|}
\hline \multirow[b]{2}{*}{ Genitores } & \multicolumn{11}{|c|}{ Efeitos da capacidade geral de combinação } \\
\hline & $\begin{array}{l}\text { MF }^{1} \\
(\mathrm{~kg})\end{array}$ & $\begin{array}{c}\text { SS } \\
\left({ }^{\circ} \text { Brix }\right)\end{array}$ & $\begin{array}{c}\text { DL } \\
(\mathrm{cm})\end{array}$ & $\begin{array}{c}\text { DT } \\
(\mathrm{cm})\end{array}$ & $\begin{array}{c}\mathrm{EF} \\
(\mathrm{cm})\end{array}$ & $\begin{array}{c}\mathbf{E P} \\
(\mathbf{c m}) \\
\end{array}$ & $\begin{array}{l}\text { NS } \\
(\mathrm{cm})\end{array}$ & $\begin{array}{l}\text { MS } \\
\text { (u) }\end{array}$ & $\begin{array}{c}\text { LS } \\
(\mathbf{m m}) \\
\end{array}$ & $\begin{array}{c}\text { CS } \\
(\mathbf{m m})\end{array}$ & $\begin{array}{l}\text { NF } \\
\text { (u) }\end{array}$ \\
\hline \multicolumn{12}{|l|}{ Grupo I } \\
\hline Cpafro $34.305(01)$ & $-0,384$ & 0,056 & $-0,064$ & $-0,176$ & $-0,013$ & $-0,036$ & 13,187 & $-0,154$ & $-0,044$ & $-0,277$ & 0,047 \\
\hline Cpafro 74.105 (02) & $-0,114$ & 0,046 & $-0,611$ & $-0,529$ & 0,053 & 0,001 & $-36,260$ & 0,309 & $-0,011$ & 0,157 & 0,083 \\
\hline Cpafro 45.202 (03) & 0,499 & $-0,101$ & 0,676 & 0,704 & $-0,040$ & 0,034 & 23,073 & $-0,154$ & 0,056 & 0,120 & $-0,130$ \\
\hline \multicolumn{12}{|l|}{ Grupo II } \\
\hline Charleston Gray (04) & 0,546 & 0,389 & 2,912 & $-0,972$ & 0,067 & 0,201 & 82,630 & 0,556 & 0,279 & 0,443 & $-0,307$ \\
\hline Sugar Baby (05) & $-0,688$ & $-0,044$ & $-2,678$ & $-0,352$ & $-0,070$ & $-0,186$ & $-141,703$ & $-0,311$ & $-0,168$ & $-0,310$ & 0,293 \\
\hline Omaru Yamato (06) & 0,142 & $-0,344$ & $-0,234$ & 1,324 & 0,003 & $-0,016$ & 59,073 & $-0,244$ & $-0,111$ & $-0,133$ & 0,013 \\
\hline Erro padrão & 0,119 & 0,199 & 0,718 & 0,415 & 0,039 & 0,047 & 19,576 & 0,125 & 0,058 & 0,094 & 0,074 \\
\hline
\end{tabular}

${ }^{1} \mathrm{MF}=$ massa do fruto (fruit weight), $\mathrm{SS}=$ sólidos solúveis (soluble solid content), $\mathrm{DL}=$ diâmetro longitudinal do fruto (axial diameter of fruit), $\mathrm{DT}=$ diâmetro transversal do fruto (transversal diameter of fruit), $\mathrm{EP}=$ espessura da casca na região do pedúnculo (rind thickness under the stalk), $\mathrm{EP}=$ espessura da casca na região da cicatriz floral (rind thickness under petals scar), NS= número de sementes por fruto (number of seeds per fruit), $\mathrm{MS}=$ massa da semente (seed weight), $\mathrm{LS}=$ largura da semente (seed width); CS= comprimento da semente (seed length) e $\mathrm{NF}=$ número de frutos por planta (number of fruits per plant). 
Tabela 3. Estimativa dos efeitos da capacidade específica de combinação em nove híbridos de melancia, para 10 características agronômicas (estimates of the effects of specific combining ability in nine hybrids of watermelon, for 10 agronomic traits). Machadinho do Oeste, Embrapa Semiárido, 2005.

\begin{tabular}{|c|c|c|c|c|c|c|c|c|c|c|c|}
\hline \multirow[b]{2}{*}{ Híbridos $^{1}$} & \multicolumn{11}{|c|}{ Efeitos da capacidade específica de combinação } \\
\hline & $\begin{array}{l}\mathbf{M F}^{2} \\
(\mathrm{~kg})\end{array}$ & $\begin{array}{c}\text { SS } \\
\left({ }^{\circ} \text { Brix }\right)\end{array}$ & $\begin{array}{c}\text { DL } \\
(\mathrm{cm})\end{array}$ & $\begin{array}{c}\text { DT } \\
\text { (cm) }\end{array}$ & $\begin{array}{c}\mathbf{E F} \\
(\mathrm{cm})\end{array}$ & $\begin{array}{c}\mathrm{EP} \\
(\mathrm{cm}) \\
\end{array}$ & $\begin{array}{l}\text { NS } \\
(\mathrm{cm})\end{array}$ & $\begin{array}{l}\text { MS } \\
\text { (u) }\end{array}$ & $\begin{array}{c}\text { LS } \\
(\mathbf{m m})\end{array}$ & $\begin{array}{c}\mathrm{CS} \\
(\mathrm{mm})\end{array}$ & $\begin{array}{l}\text { NF } \\
\text { (u) }\end{array}$ \\
\hline $01 \times 04$ & $-0,396$ & 0,291 & 0,811 & 0,386 & $-0,003$ & $-0,121$ & $-44,297$ & 0,201 & $-0,042$ & 0,130 & 0,727 \\
\hline $02 \times 04$ & 0,618 & 0,254 & 0,201 & 0,396 & 0,023 & 0,156 & $-39,963$ & $-0,032$ & 0,035 & 0,023 & $-0,603$ \\
\hline $03 \times 04$ & $-0,222$ & $-0,546$ & $-1,012$ & $-0,781$ & $-0,020$ & $-0,034$ & 84,260 & $-0,169$ & 0,008 & $-0,153$ & $-0,123$ \\
\hline $01 \times 05$ & 0,194 & 0,131 & 0,158 & 0,409 & 0,030 & 0,002 & $-17,520$ & $-0,032$ & 0,054 & $-0,163$ & $-0,470$ \\
\hline $02 \times 05$ & $-0,182$ & $-0,066$ & $-0,822$ & $-0,651$ & 0,087 & 0,009 & $-37,187$ & 0,064 & $-0,099$ & 0,020 & 0,130 \\
\hline $03 \times 05$ & $-0,012$ & $-0,066$ & 0,664 & 0,242 & $-0,117$ & $-0,011$ & 54,707 & $-0,032$ & 0,044 & 0,143 & 0,340 \\
\hline $01 \times 06$ & 0,201 & $-0,422$ & $-0,969$ & $-0,795$ & $-0,027$ & 0,119 & 61,817 & $-0,169$ & $-0,012$ & 0,033 & $-0,257$ \\
\hline $02 \times 06$ & $-0,436$ & $-0,189$ & 0,621 & 0,256 & $-0,110$ & $-0,164$ & 77,150 & $-0,032$ & 0,065 & $-0,043$ & 0,473 \\
\hline $03 \times 06$ & 0,234 & 0,611 & 0,348 & 0,539 & 0,137 & 0,046 & $-138,967$ & 0,201 & $-0,052$ & 0,010 & $-0,217$ \\
\hline Erro padrão & 0,168 & 0,282 & 1,015 & 0,587 & 0,055 & 0,066 & 27,685 & 0,176 & 0,082 & 0,133 & 0,105 \\
\hline
\end{tabular}

em que participa, esta linhagem tende a contribuir para a elevação do teor de sólidos solúveis, diminuição do tamanho dos frutos e do numero de sementes e aumento da prolificidade, sendo, pois um genitor com maior potencial de aproveitamento em programas de melhoramento que visem à obtenção de cultivares que atendam à crescente demanda do mercado por frutos menores.

Com relação à linhagem Cpafro 45.202, efeitos negativos de CGC foram observados para sólidos solúveis, espessura de casca na região da cicatriz floral, massa de sementes e número de frutos por planta. Efeitos positivos de CGC foram verificados para massa, diâmetro transversal e diâmetro longitudinal de fruto; espessura de casca no pedúnculo; número, largura e comprimento de sementes; e número de frutos por planta (Tabela 2), o que evidencia, principalmente, a tendência deste genitor contribuir para a produção de genótipos menos prolíficos, com frutos maiores e menos doces, o que não atenderia às demandas de mercado.

No caso da cultivar 'Charleston Gray', verificam-se efeitos positivos para massa e diâmetro longitudinal do fruto; sólidos solúveis, espessura de casca (EC e EP), número de sementes por fruto e tamanho de sementes (MS, DL e DT) (Tabela 2), demonstrando que esse genótipo pode contribuir para a produção de populações de frutos grandes, alongados, doces, de casca espessa, contendo sementes numerosas e grandes. Esse genitor poderá ser aproveitado no melhoramento que vise a atender à demanda vigente por frutos grandes, a qual deverá prevalecer por muito tempo, haja vista a expansão da oferta de melancia fatiada nos supermercados, feiras livres e quitandas.

Com relação à cultivar 'Sugar Baby', observaram-se efeitos positivos de CGC apenas para o número de frutos por planta (Tabela 2), evidenciando que este genótipo poderá contribuir para a obtenção de genótipos prolíficos, de frutos pequenos, casca mais fina, contendo sementes menores e menos numerosas. Resultados semelhantes foram obtidos por Souza et al. (2002), avaliando a capacidade de combinação desse genitor com um grupo de genótipos tetraploides, para obtenção de híbridos triploides. O satisfatório desempenho da cultivar 'Sugar Baby' em diversos cruzamentos reforça a sua qualificação como um genitor adequado para uso em progra- mas de melhoramento que visem ao desenvolvimento de cultivares de frutos menores. Além disso, por apresentar razoável prolificidade, também poderá ser usada na obtenção de híbridos prolíficos.

Para o genótipo 'Omaru Yamato', foram observados efeitos positivos da CGC para massa do fruto, diâmetro transversal do fruto e numero de sementes. Efeitos negativos foram constatados para sólidos solúveis; massa, comprimento e largura das sementes (Tabela 2), evidenciando que este genitor tende a contribuir para a obtenção de genótipos de frutos maiores, menos doces, com sementes mais numerosas e de menor tamanho.

As estimativas da CEC evidenciam a importância dos genes que exibem efeitos não-aditivos e devem ser interpretadas como desvios no desempenho do híbrido em relação ao que seria esperado com base na CGC dos seus genitores (Sprague \& Tatum, 1942). Desse modo, elevados valores absolutos de CEC indicam que o híbrido apresentou comportamento diferente do que era esperado em relação aos seus genitores. Por outro lado, valores de CEC próximos de zero sugerem que o desempenho do híbrido ocorreu conforme esperado. Em relação 
aos efeitos da CEC, obtidos por meio de cruzamentos de diferentes genitores, Cruz \& Vencovsky (1989) afirmam que os híbridos mais promissores serão aqueles que apresentam elevados efeitos (positivos ou negativos, a depender da característica em questão) da CEC e que sejam provenientes do cruzamento de genitores divergentes, no qual, pelo menos um deles apresente elevada CGC.

Com relação à massa do fruto, os resultados da CEC (Tabela 3) podem ser analisados sob duas perspectivas. Para o mercado de frutos grandes, os híbridos mais interessantes serão aqueles com maiores efeitos positivos da CEC, que descendam do genitor de maior CGC. Em contraste, para o mercado de frutos pequenos, os híbridos mais promissores serão aqueles com maior CEC negativa, derivados do genitor de maior CGC negativa. Desse modo, poderiam ser selecionadas as combinações Cpafro 74.105 x Charleston Gray, para o primeiro caso, e Cpafro 74.105 x Sugar Baby, para o segundo.

Os sólidos solúveis estão bastante correlacionados com a doçura dos frutos e são uma das principais características que compõem a qualidade e o valor comercial da melancia, de modo que os frutos mais doces são os mais apreciados pelos consumidores. Maior efeito de CEC para sólidos solúveis foi verificado no cruzamento Cpafro 45.202 x Omaru Yamato (Tabela 3), demonstrando que o desempenho do mesmo foi superior ao que seria esperado com base na CGC dos seus genitores, que apresentaram baixa CGC. As combinações de Charleston Gray (que apresentou a maior CGC entre os genitores para sólidos solúveis) e as linhagens Cpafro 34.305 e Cpafro 74.105 também apresentaram efeitos satisfatórios de CEC, o que poderia viabilizar o seu uso futuro para fins comerciais.

Com relação ao diâmetro longitudinal de fruto (comprimento do fruto) tem-se observado que frutos de formato mais compridos, dada a sua dificuldade de manuseio e transporte, têm sido preteridos pelos consumidores, que têm procurado, principalmente, frutos de formato redondo e oblongo. Nesse caso, efeitos negativos de CEC para o diâmetro longitudinal do fruto são desejáveis nos híbridos. Como o genitor 'Sugar Baby' apresentou menor efeito da CGC para diâmetro longitudinal do fruto, observa-se que o híbrido mais adequado para exploração comercial, considerando-se apenas essa característica, seria aquele obtido pelo cruzamento daquela cultivar com a linhagem Cpafro 74.105 .

O diâmetro transversal, ou largura, do fruto está relacionado com espessura da polpa, de modo que frutos mais largos têm maior volume de polpa. Para esta característica, destacou-se a combinação Cpafro 45.202 x Omaru Yamato, com maiores efeitos de CEC e advinda de dois genitores com elevados efeitos de CGC.

A espessura de casca é uma característica importante para a resistência dos frutos ao manuseio e ao transporte. De fato, entre as cultivares utilizadas no Brasil, aquelas de frutos com casca mais espessa são mais adequadas ao tipo de transporte predominante no mercado interno (frutos a granel transportados em caminhões sem refrigeração, por longas distâncias). Para essa característica, destacou-se a combinação Cpafro 74.105 x Charleston Gray, que apresentou maior efeito da CEC e teve um dos seus genitores ('Charleston Gray') com maior efeito de CGC.

Sendo a presença de semente uma característica desfavorável ao consumo da melancia, genótipos com menor número de sementes por fruto são preferidos. A combinação Cpafro 45.202 x Omaru Yamato apresentou efeitos negativos elevados de CEC para número de sementes por fruto, demonstrando que o desempenho do mesmo diferiu daquele que seria esperado com base na CGC dos seus genitores, que apresentaram efeitos positivos de CGC. Mereceram destaques os híbridos Cpafro 34.305 x Sugar Baby e Cpafro 74.105 x Sugar Baby (Tabela 3), que apresentaram efeitos negativos de CEC, sendo que pelo menos um de seus genitores ('Sugar Baby') apresentou elevada CGC negativa.

Além da quantidade, o tamanho da semente é outro fator de depreciação dos frutos de melancia. Genótipos de sementes menores têm a preferência dos consumidores. Portanto, nesse caso, efeitos negativos da CEC são mais interessantes para o melhoramento. Para massa, largura e comprimento de sementes verificaram-se maiores efeitos negativos de CEC nas combinações Cpafro 45.202 x Charleston Gray, Cpafro 34.305 x Sugar Baby e Cpafro 34.305 x Omaru Yamato (Tabela 3), sendo que, para as três variáveis 'Sugar Baby' e Cpafro 34.305 foram os genitores com efeitos de CGC mais satisfatórios (elevados e negativos).

Os efeitos da CGC foram superiores aos da CEC na maioria das características estudadas, evidenciando a predominância da interação aditiva sobre a não-aditiva, no controle daqueles caracteres. Tal fato sugere que, no caso do germoplasma avaliado, haverá facilidade de realizar o melhoramento genético da cultura por meio de técnicas simples de seleção. Com base no conjunto de características avaliadas, para o melhoramento intrapopulacional, no grupo I, destacou-se a linhagem Cpafro 74.105 , como a mais promissora para utilização em programas de melhoramento que visem à obtenção de frutos pequenos. No grupo II, são indicados os genitores 'Sugar Baby', para o desenvolvimento de cultivares de frutos pequenos, e 'Charleston Gray', para cultivares de frutos grandes. As combinações híbridas superiores e, portanto, com maior potencial de aproveitamento comercial foram: Cpafro $74.105 \mathrm{x}$ Charleston Gray, de frutos grandes e Cpafro 74.105 x Sugar Baby, de frutos pequenos, doces e com reduzido número de sementes.

\section{REFERÊNCIAS}

BAHARI M; RAFII MY; SALEH GB; LATIF MA. 2012. Combining ability analysis in complete diallel cross of watermelon (Citrullus lanatus (Thunb.) Matsum. \& Nakai). The Scientific World Journal. Disponível em http://tswj. com/2012/543158. Acessado em 01 de agosto de 2012.

BRAR JC; SIDHU AS. 1977. Heterosis and combining ability of earliness and quality characters in watermelon (Citrullus lanatus (Thunb.) Mansf.). II. Journal of Research Punjab Agricultural University 14:272-278.

CRUZ CD; VENCOVSKY R. 1989. Comparação de alguns métodos de análise dialélica. Revista Brasileira de Genética 12: 425-436.

CRUZ CD; REGAZZI AJ; CARNEIRO PCS. 2004. Modelos Biométricos Aplicados ao 
Melhoramento Genético - Volume 1. Viçosa: UFV. 390p.

CRUZ CD. 2013. Genes: a software package for analysis in experimental statistics and quantitative genetics. Acta Scientiarum Agronomy 35: 271-276.

FAO - Food Agriculture Organization. 2013, 28 de junho. Countries by commodities Top Production - Watermelons 2010. Disponível em: http://www.faostat. fao.org/site/339/default.aspx

FERREIRA MAJ; BRAZ LB; QUEIROZ MA; CHURATA MASCA MGC; VENCOVSKY R. 2002. Capacidade de combinação em sete populações de melancia. Pesquisa Agropecuária Brasileira 37: 963-970.

GRIFFING BA. 1956. Concept of general and specific combining ability in relation to diallel crossing systems. Australian Journal of Biological Science 9: 463-493.

GAMAFC; VISA R. 2008. Cultivares. In: SOUZA FF (ed). Cultivo da melancia em Rondônia. Porto Velho: Embrapa Rondônia. p. 96-102.

GILL BS; KUMAR JC. 1988. Combining ability analysis in watermelon (Citrullus lanatus Thunb. Mansf.). Indian Journal of Horticulture 45: 104-109.

GUSMINI G; WEHNER T. 2005. Foundations of yield improvement in watermelon. Crop Science 45: 141-146.

GVOZDANOVIC-VARGA J; VASIC M; MILIC D; CERVENSKI J. 2011. Diallel cross analysis for fruit traits in watermelon. Genetika 43: 163-174.

IBGE - Instituto Brasileiro de Geografia e Estatística. 2013, 28 junho. Produção agrícola municipal. 2011. Disponível em: http:// www.ibge.gov.br/home/estatistica/economia/ pam/2011

NANDPURI KS; KUMAR JC; DHILLON GS. 1975. Combining ability estimates in a set of top crosses in watermelon (Citrullus lanatus Sch.). Journal of Research Punjab Agricultural University 15: 65-70.

SACHAN SCP; NATH P. 1976. Combining ability of some quantitative characters in 10 x 10 diallel crosses of watermelon, Citrullus lanatus (Thunb.) Mansf. Egyptian Journal of Genetics and Cytology 5: 65-79.
SHABAN WIA; ABDELSSALAM MMM. 2009. Evaluation of combining ability of some agronomic traits and susceptibility to Fusarium wilt in watermelon hybrids. Tunisian Journal of Plant Protection 4: 15-28.

SIDHU AS; BRAR JS. 1977. Heterosis and combining ability of yield and its components in watermelon (Citrullus lanatus (Thunb.) Mansf.). Journal of Research Punjab Agricultural University. 14: 52-58.

SOUZA FF; QUEIROZ MA; DIAS RCS. 2002. Capacidade de combinação entre linhas tetraplóides e diplóides de melancia. Horticultura Brasileira 20: 654-658.

SOUZA FF; GAMA FC; QUEIROZ MA. 2004. Análise de combinação em cruzamentos dialélicos de três genótipos de melancia. Horticultura Brasileira 22: 789-793.

SOUZA FF. 2008. Cultivo da melancia em Rondônia. Porto Velho: Embrapa Rondônia. p. 34-44.

SPRAGUE GF; TATUM LA. 1942. General vs. specific combining ability in single crosses of corn. Journal of the American Society of Agronomy 34: 923-932. 